\title{
Cointegration Analysis between the Structure of Manufacturing Industry and the Urban Environment in Anhui Province, China based on VAR \& VEC Model
}

\author{
Sufeng Wang, a, Tingjin Liü, ${ }^{1,}$, Yue $\mathrm{Xu}^{1, \mathrm{c}}$, Jianming Ye ${ }^{1, \mathrm{~d}}$, Chu Chü, e \\ ${ }^{1}$ School of Economy and Management, Anhui Jianzhu University, Hefei 230601, Anhui, China \\ ${ }^{2}$ Science and Technology Department, Anhui Jianzhu University, Hefei 230601, Anhui, China \\ awangsufeng927@ahjzu.edu.cn, b1792895853@qq.com, '971704577@qq.com, dyejm@263.net, \\ '9chuchu@ahjzu.edu.cn
}

Keywords: Structure of manufacturing industry; Ecological environment; VAR-VEC; Cointegration test; Impulse response; Variance decomposition.

Abstract. There is a close relationship between industrial structure and ecological environment. Based on the data of the structure of manufacturing industry and the ecological environment during 2000-2015 in Anhui province of China, the VAR and VEC models are constructed. The cointegration test found that, there is significant industrial difference in the equilibrium relationship among structural variables (i.e. the proportion of value added of textile industry, resource processing industry, and machinery and electronic industry) and environmental variables (i.e. water environment, atmospheric environment, and solid environment). On this basis, the Granger causality test was carried out to examine the causal association between variables. Further, with the help of impulse response function and variance decomposition, the direction, degree and contribution of the impulse response among variables are analyzed.

\section{Introduction}

Recently, the environmental problems caused by the change of industrial structure (especially the structure of manufacturing sector) have drawn more and more attention from academic communities [1]. While the manufacturing sector in Anhui province of central China has witnessed a rapid growth, the economic mode of high input, high consumption and low technical content has brought a significant impact on the ecological environment to most of the cities. Accordingly, there is a pressing need to find out the structural difference and evolution law of industrial structure and environment.

This paper has three main contributions. Firstly, the mechanism between the manufacturing sector and urban environment during 2000 to 2015 is explored. Secondly, the long-term equilibrium relation between the two sub-systems will be examined by cointegration analysis, and the VAR-VEC models be formed for the Granger causality test. Thirdly, using by the impulse response function and variance decomposition methods, the degree and the contribution of variables in the relationship will be investigated as well.

\section{Data}

For comparison, the manufacturing industry (including 31 sub-sectors) is divided into three categories (see Table 1), which correspond to labor-intensive, energy-intensive and technology- intensive industries. The proportion of the value added of these three sub-categories to the total manufacturing value added is the presentation of manufacturing structure, which denoted by $X^{t}, X^{r}, X^{m}$, respectively. Meanwhile, the industrial waste water emissions, industrial waste gas emissions, and solid waste emissions per 10 thousand industrial value added are chosen to be as the representative of environmental variables, which denoted by $Y^{w}, Y^{g}, Y^{s}$, respectively.

In order to investigate the correlation mechanism between the structure of manufacturing sector and environment in Anhui province, a vector autoregressive (VAR) model is proposed. This paper takes 
the industrial and ecological data of Anhui province during 2000 to 2015 as the sample. Data is mainly from the "Statistical Yearbook of Anhui Province" and "Chinese City Statistical Yearbook" (2000-2015), with the interpolation method of filling missing data being applied. All variables are treated by natural logarithm in order to lower the impact of heteroscedasticity. The logarithmic process can also reflect the change elasticity of the variables in the long term, which is beneficial to the analysis of the lag of the interaction between industry and environment. The logarithmic transformation of these variables is as

$$
\begin{aligned}
& L X^{t}=\ln \left(X^{t}\right), L X^{r}=\ln \left(X^{r}\right), L X^{m}=\ln \left(X^{m}\right) \\
& L Y^{w}=\ln \left(Y^{w}\right), L Y^{g}=\ln \left(Y^{g}\right), L Y^{s}=\ln \left(Y^{s}\right)
\end{aligned}
$$

\begin{tabular}{|c|c|}
\hline Categories & Sub industry \\
\hline $\begin{array}{c}\text { Textile } \\
\text { manufacturing }\end{array}$ & $\begin{array}{l}\text { Agricultural food processing industry } \\
\text { Food industry } \\
\text { Wine, beverage and refined tea industry } \\
\text { Tobacco products industry } \\
\text { Textile industry } \\
\text { Textile and dress industry } \\
\text { Leather fur feather and its products and footwear industry } \\
\text { Wood processing, bamboo and rattan, and brown grass products industry } \\
\text { Furniture industry } \\
\text { Paper and its products industry } \\
\text { Printing and recording media reproduction industry } \\
\text { Activities of sports and entertainment supplies manufacturing industry }\end{array}$ \\
\hline $\begin{array}{c}\text { Resource } \\
\text { processing }\end{array}$ & $\begin{array}{l}\text { Petroleum processing, coking and nuclear fuel processing industry } \\
\text { Chemical raw materials and chemical products manufacturing industry } \\
\text { Pharmaceutical manufacturing industry } \\
\text { Chemical fiber manufacturing industry } \\
\text { Rubber and plastic products industry } \\
\text { Non-metallic mineral products industry } \\
\text { Ferrous metal smelting and rolling processing industry } \\
\text { Non-ferrous metal smelting and rolling processing industry } \\
\text { Metal products industry }\end{array}$ \\
\hline $\begin{array}{l}\text { Machinery and } \\
\text { electronic } \\
\text { manufacturing }\end{array}$ & $\begin{array}{l}\text { General equipment manufacturing industry } \\
\text { Special equipment manufacturing industry } \\
\text { Automobile manufacturing industry } \\
\text { Rail, vessel, aerospace and other transport equipment manufacturing industry } \\
\text { Electrical machinery and equipment manufacturing industry } \\
\text { Computer communications and other electronic equipment manufacturing industry } \\
\text { Instruments manufacturing industry } \\
\text { Other manufacturing industry } \\
\text { Comprehensive utilization of waste resources industry } \\
\text { Metal products, machinery and equipment repair industry }\end{array}$ \\
\hline
\end{tabular}

Table 1. The division of the manufacturing industry

\section{Results and discussion}

Unit root test. Based on the unit root test, the null hypothesis is rejected under all methods. However, all first-differencing series are stationary, indicating that these variables are $I(1)$ processes.

Cointegration test. According to the least AIC and SC criterion, the optimal lag (1 order) is determined, so the $\operatorname{VAR}(1)$ model is established. For simplicity, we take environmental variables as dependent variables and industrial variables as independent. Then the JJ cointegration test is carried out by using the method of trace statistic and the maximum eigenvalue method for this model.

It is found that there is a long-term equilibrium relationship between variables of water environment and structure of manufacturing sector (see Table 2). Hence, the short-term relationship between these variables of the VEC model can be further constructed. 
According to the result of cointegration test, there is an equilibrium relationship between water environment and structure of manufacturing sector as

$$
\Delta L Y^{w}(-1)=-1.902 \Delta L X^{t}(-1)+1.439 \Delta L X^{r}(-1)-0.734 \Delta L X^{m}(-1)
$$

Where $\Delta L Y^{w}$ represents the first-lag of $L Y^{w}$, the same below.

It is clear that among three sub sectors of manufacturing industry, the textile manufacturing industry and the machinery and electronic industry negatively relation to water environment, while the resource processing industry has a positive correlation with water environment.

Table 2. JJ cointegration test between water environment and manufacturing structure

\begin{tabular}{ccccc}
\hline Hypothesized No. of CE(s) & Eigenvalue & Trace Statistic & 0.05 Critical Value & Prob.** \\
\hline None* & 0.772 & 29.928 & 29.797 & 0.048 \\
At most 1 & 0.346 & 7.778 & 15.495 & 0.490 \\
At most 2 & 0.090 & 1.419 & 3.841 & 0.234 \\
\hline Hypothesized No. of CE(s) & Eigenvalue & Max-Eigen Statistic & $\mathbf{0 . 0 5}$ Critical Value & Prob.** \\
\hline None* & 0.772 & 22.151 & 21.132 & 0.036 \\
At most 1 & 0.346 & 6.359 & 14.265 & 0.568 \\
At most 2 & 0.090 & 1.419 & 3.841 & 0.234 \\
\hline
\end{tabular}

Note: Trace \& Max-eigenvalue test indicate 1 co-integrating eqn(s) at the 0.05 level.

Also, JJ cointegration test shows that there is a long-term equilibrium relationship between variables of atmospheric environment and structure of manufacturing sector, and the VEC model should be built again. The cointegration relationship between variables is as

$$
\Delta L Y^{g}(-1)=0.612 \Delta L X^{t}(-1)+0.312 \Delta L X^{r}(-1)-1.735 \Delta L X^{m}(-1)
$$

According to the test result, the textile industry and the resource processing industry has positive relation to atmospheric environment, while the machinery and electronic manufacturing industry negatively correlated to environment.

Unlike the discovery of literature [2], there is no long-term cointegration relationship between variables of solid environment and structure of manufacturing sector. The possible reason for this is that, important changes have happened in the structure of Anhui manufacturing industry. Some sub industries, such as the petroleum processing industry, have significantly shrank.

Granger causality test. As all variables are $I(1)$ series, the Granger causality analysis can be carried out. Results show that: (i) $\Delta L Y^{w}$ is the one-way Granger cause of $\Delta L X^{m}$, and $X^{t}$ is the one-way Granger cause of $\Delta L Y^{w}$; (ii) there is no Granger causality relationship between variables of atmospheric environment and structure of manufacturing sector; (iii) $\Delta L X^{m}$ is the one-way Granger cause of $\Delta L Y^{s}$. In accordance with literature [3], the causal link between the manufacturing industry and the environment can be found when the industry is taken as a whole; nevertheless, different causality patterns appear when the industry is separated into three sub sectors in this paper.

Impulse response function. For those sequences which are stationary after first-differencing process, if there is no cointegration relationship among variables, the VAR model can be established. However, the impulse response analysis and variance decomposition can be done only when the VAR model is stable. According to the stability test of the VAR model for variables of solid environment and structure of manufacturing sector, the model is non-stable. Therefore, we only discuss the impulse response and variance decomposition between water/atmospheric environment and industrial variables.

Using the EViews software, the impulse response between water environment and structure of manufacturing sector is obtained (see Figure 1 and Figure 2). The vertical and horizontal axes respectively represent the degree of impulse response and the number of lag periods, and the solid line 
and dashed line are respectively the impulse response function and plus or minus 2 times of the standard deviation, the same below.
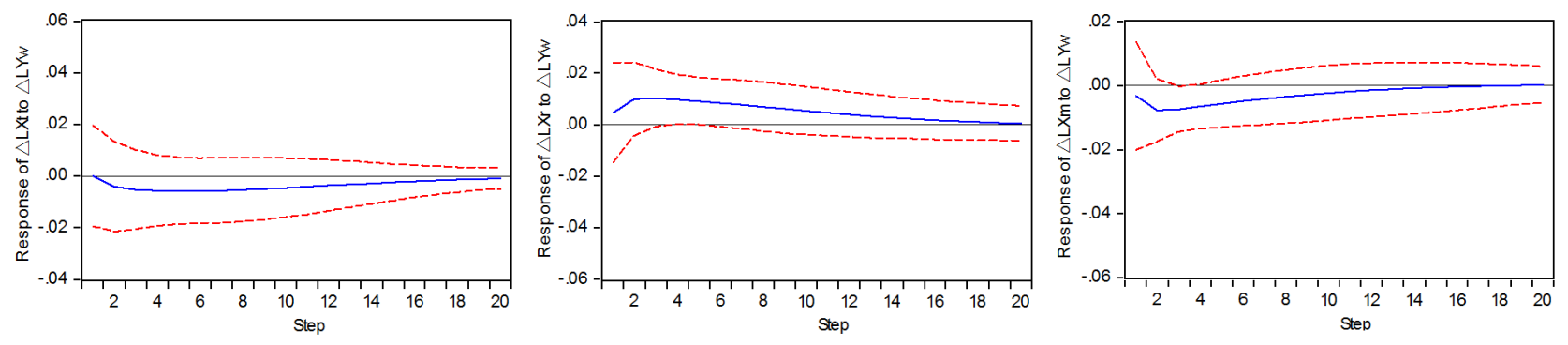

Fig.1. The response of different sub sectors to water environment
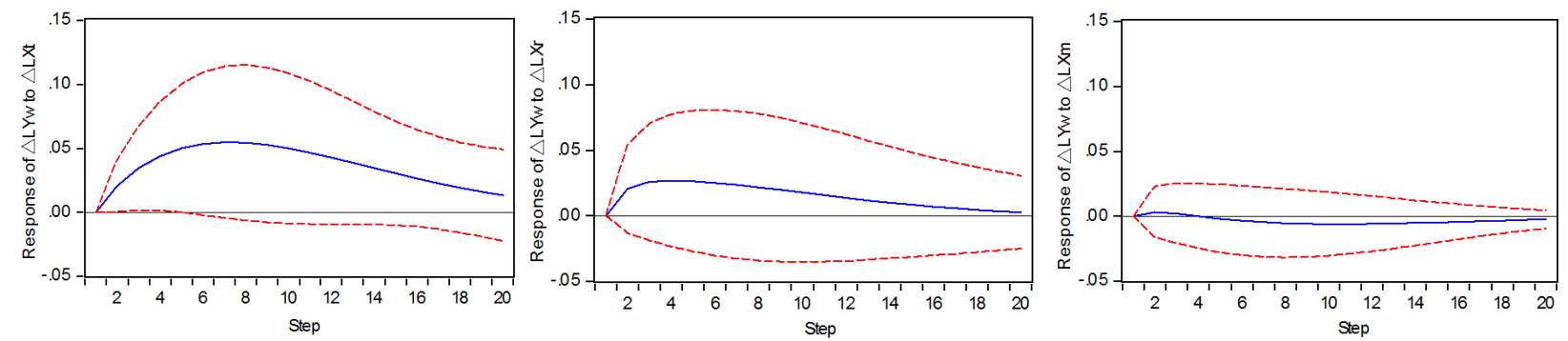

Fig.2. The response of water environment to different sub sectors

Figure 1 conveys three key points. Firstly, based on the response of $\Delta L X^{t}$ to an innovation of $\Delta L Y^{w}$, the first-step reaction is at a small negative level, then begins to decline gradually, and reaches the lowest value before back to the equilibrium at the twentieth-step, with the negative cumulative response been witnessed. Secondly, based on the response of $\Delta L X^{r}$ to an innovation of $\Delta L Y^{w}$, the maximum response is reached at step 2, then decreases and converges slowly, with the positive cumulative response left. Thirdly, based on the response of $\Delta L X^{m}$ to an innovation of $\Delta L Y^{w}$, the minimum value appears at step 2 as well, while the response starts to climb up and converge rapidly, with a negative cumulative response presented. It can be concluded that, the impulse of waste water discharge will stimulate the development of resource processing industry, but this effect keeps decreasing; on the contrary, the wastewater emissions has negative relations to the expand of other two sub industries. This is consistent with the formula (3) and the main findings of literature [4].

Next we turn to Figure 2. There exist positive cumulative responses of waste water emissions to both textile and resource processing industries, while the impact by textile manufacturing industry is larger than that by resource processing industry. By contrast, the response of waste water emissions to machinery and electronic industry is very weak; meanwhile the cumulative response is negative. This means that, if strict regulations on the industrial waste water are imposed in the textile manufacturing industry, the abatement effect will be most significant.

Similarly, the impulse response analysis of variables between industrial structure and atmospheric environment is estimated. On one hand, the cumulative response of both textile and resource industries to an innovation in atmospheric environment is positive. The response of textile manufacturing industry to an innovation in waste gas reaches at the maximum value at step 3, and converges to the equilibrium at step 7; while the response of waste gas to resource industry is much smaller and converges slowly. Unlike the two industries, the response of waste gas to machinery and electronic industry meets the lowest point at the fourth step, and then increases smoothly; while the cumulative response is negative, which is similar to the results of literature [5]. Therefore, the increase of waste gas emissions positively affect the proportion of textile manufacturing industry and resource processing industry, while the atmospheric environment has negative impact on the development of machinery and electronic manufacturing industry. This confirms the formula (4). 
On the other hand, the response trends of industrial waste gas to textile manufacturing industry and machinery and electronic industry are very close, characterized by gradually increase before quick decrease. The response of industrial waste gas to textile manufacturing industry reaches the minimum value at step 3, and converges to a weak negative level at step 8 meanwhile shows a negative cumulative response; however, the response of industrial waste gas to machinery and electronic industry turns to positive from negative and converges at the fourth step, with the positive cumulative response presented. Different from the two sub sectors, the response of industrial waste gas to resource industry declines with fluctuations, and the maximum response appear at the first period and the lowest value at the tenth stage, with a positive cumulative response produced. Hence, if serious restriction on industrial waste gas in the resource processing industry is issued, the air pollution should be reduced to the greatest extent.

Variance decomposition. In order to emphasize the structural effects on environment and facilitate the comparisons of these effects at the same time, the following will focus on the contribution of the manufacturing structure to the variations of environment.

As Figure 3 shows that, except the impact on water environment by itself, the contribution degree of textile manufacturing industry is the largest among the factors that causing water environment to fluctuate, followed by the resource processing industry, while the proportion of machinery industry has almost no impact on the water environment. This again confirms the formula (3).
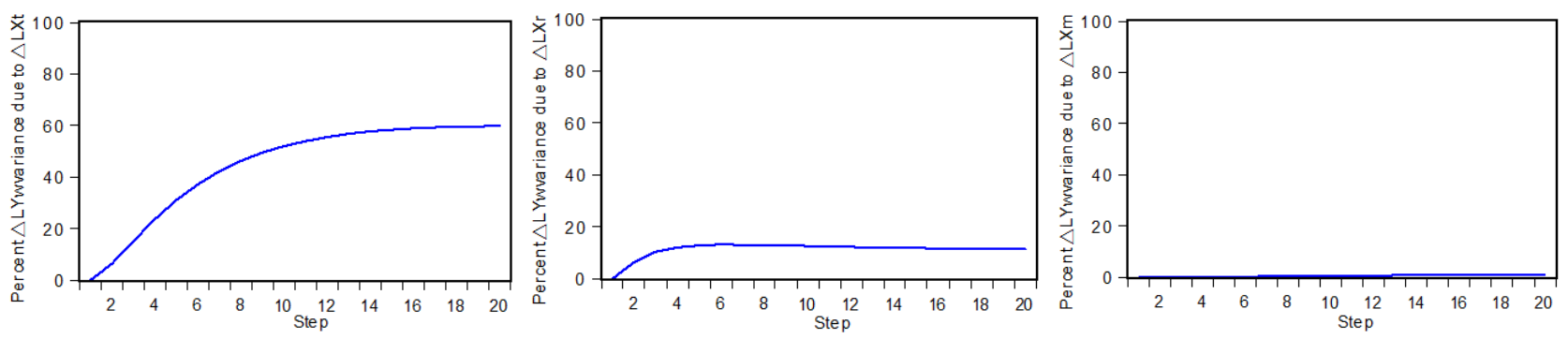

Fig.3. Variance decomposition of the change in water environment by manufacturing structure

Figure 4 shows that, as to the fluctuation of atmospheric environment, the impact and their differences of each manufacturing industry are not significant. Consequently, the change of atmospheric environment in Anhui province is mainly affected by the fluctuation of the atmosphere itself, indicating that the impact of the manufacturing structure on the atmospheric environment is small. This finding is similar to the basic logic of literature [6]. It is worth noting that however, as the proxy of atmospheric environment in this paper is the waste gas emissions per 10 thousand industrial value added, the conclusion may be changed if the proxy variable is replaced [7]; furthermore, the small changes in the contribution rate of three sub sectors does not mean that manufacturing industry has little effect on the atmosphere, but that the effect of structural change is not so significant as the effect of atmosphere itself. In fact, some atmospheric problems emerged in recent years are closely related to the structural changes in Anhui province, which can be seen from the temporal and spatial variations in ecology and manufacturing industry.
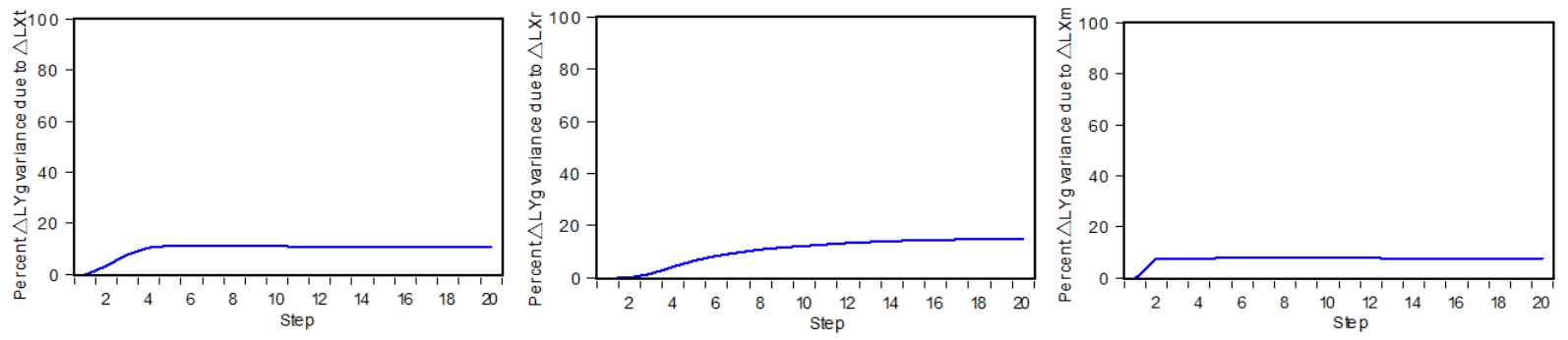

Fig.4. Variance decomposition of the change in air environment by manufacturing structure 


\section{Conclusions}

Based on the data of Anhui province's manufacturing industry and ecological environment in 2000-2015, this paper constructs the VAR-VEC models between variables, and analyzes the interaction mechanism between the two sub systems. The main conclusions are as follows:

First of all, the cointegration test shows that there is long-term stable equilibrium relationship between structural and water environmental variables, and between structural and atmospheric environmental variables as well. However, the cointegration test between structure of manufacturing sector and solid environment is not significant.

Secondly, causality test found that there is one-way Granger causal relationship between industrial waste water and the value added of machinery and electronic industry, and between the value added of textile manufacturing industry and waste water emissions. Meanwhile, the machinery and electronic industry is the only sub sector that Granger causes the solid environment. However, there is no Granger causality between structural variables and atmospheric variables.

Thirdly, the impulse response analysis shows that, the structural effects of different sub sectors on both industrial waste water and atmospheric environment are significant. In terms of ecological regulations, the restriction on wastewater in the textile manufacturing industry will produce the greatest mitigation effect; while the control on waste gas in the resource processing industry will reduce air pollution most.

Finally, the results of variance decomposition indicate that, the textile manufacturing industry contributes most to the fluctuation of water environment, followed by resource processing sector. Conversely, the response of atmospheric environment to three sub sectors is relative weak compared to that caused by the atmosphere itself.

\section{Acknowledgements}

This research was supported by the National Natural Science Foundation of China (71601066), the Ministry of Education of China (15YJA790060), and the Education department of Anhui province of China (gxfxZD2016130; SK2017A0553; SK2016A0223).

\section{References}

[1] R. Laurenti, M. Redwood, R. Puig and B. Frostell: Journal of Industrial Ecology Vol. 21(2017), 1180-1187.

[2] Z. Zhu, Z. Li, X. Bi, et al. : Journal of Hazardous Materials Vol. 246-247(2013), 189-198.

[3] W. Song and B. Sung: The Journal of International Trade \& Economic Development Vol. 23(2014), 923-945.

[4] B. Yu, X. Li, Y. Qiao and L. Shi: Journal of Environmental Sciences Vol. 28(2015), 137-147.

[5] B.C. Ghosh, K.J. Alam and M.A. Osmani: International Journal of Business and Economics Research Vol. 3(2014), 220-227.

[6] K.S. Calbick and T. Gunton: Energy Policy Vol. 67(2014), 895-902.

[7] M.R. Alves and V. Moutinho: Energy Vol. 57(2013), 775-787. 